ORIGINAL ARTICLE

\title{
Assessment of Pediatrics Radiation Dose from Routine X-Ray Examination at Jimma University Hospital, Southwest Ethiopia
}

\author{
Mesfin Zewdu ${ }^{1}$, Elias Kadir ${ }^{1}$, Melkamu Berhane ${ }^{2}$
}

\section{OPEN ACCESS}

Citation: Mesfin Zewdu, Elias Kadir, Melkamu Berhane. Assessment of Pediatrics Radiation Dose from Routine X-Ray Examination at Radiology Department of Jimma University Specialized Hospital, Southwest Ethiopia. J Health Sci 2017;27(5):481. doi:http://dx.doi.org/10.4314/ejhs.v27i5.6 Received: March 2, 2017

Accepted: March 5, 2017

Published: September 1, 2017

Copyright: (C) 2017 Mesfin Zewdu, et al. This is an open access article distributed under the terms of the Creative Commons Attribution License, which permits unrestricted use, distribution, and reproduction in any medium, provided the original author and source are credited. Funding: the funding source for this study was Jimma University, College of Health Sciences.

Competing Interests: The authors declare that this manuscript was approved by all authors in its form and that no competing interest exists.

Affiliation and Correspondence:

${ }^{1}$ Department of Radiology Jimma Univerity, Ethiopia

${ }^{2}$ Department of Pediatric and Child Health, Jimma University, Ethiopia

*Email: zewdumesfin5@gmail.com

\begin{abstract}
BACKGROUND: Given the fact that children are more sensitive to ionizing radiation than adults, with an increased risk of developing radiation-induced cancer,special care should be taken when they undergo X-ray examinations. The main aim of the current study was to determine Entrance Surface Dose (ESD) to pediatric patients arising from routine $x$-ray examination in the Radiology Department of Jimma University Specialized Hospital (JUSH).
\end{abstract}

METHODS: Descriptive cross-sectional study was conducted on pediatric patients less than 15 years of age who visited to seek $x$ ray examinations in JUSH. In this study, chest (AP), skull (AP), Abdomen (AP) and Pelvic (AP) $x$-ray examinations were analyzed. Radiographic exposure factors were recorded in each examination. ESD was calculated using exposure parameters. The calculated ESD values were weighed against the Diagnostic Reference Level (DRL) recommended doses and similar published studies. Comparison was made among different age groups through mean comparison.

RESULT: The obtained ESD values were mostly higher than the values in internationally published studies and DRL for all age groups. For chest AP, the mean ESD values were $1.82 \mathrm{mGy}$ which is higher than similar studies in Nigeria (0.642Mgy), Brazil (o.o62mGy) and NRPB (0.050mGy) for ages of 0-1 years.

CONCLUSION: The higher pediatric patient dose obtained in this study is a further indicator that doses delivered to pediatric patients are not according to ALARA principle, and there is a need to optimize service and patients' radiation exposure in JUSH in particular and in Ethiopia in general.

KEYWORDS: Pediatrics, Radiation Dose, Exposure Parameters, X-ray, Jimma, Ethiopia

\section{INTRODUCTION}

In both developed and developing countries, the number and range of $\mathrm{X}$-ray facilities and X-ray equipment is increasing rapidly (1). Although alternative modalities for diagnosis of diseases and injury, such as ultrasound and MRI are becoming increasingly available,

DOI: http://dx.doi.org/10.4314/ejhs.v27i5.6 
steady improvement in the quality of X-ray images and patient protection have ensured that diagnostic X-rays remain the most frequently used tools in diagnosis (2) and hence make a major contribution to human being's exposure to ionizing radiation from human-made sources. Xray used for medical diagnosis delivers some percentage of its energy to the patient body, the quantity that expresses that the concentration of this energy in the body is the absorbed dose. It has been shown that this absorbed energy causes genetic and other harmful effects to human cells (3).

The prevention of the potential hazardous effect of ionizing radiation has been a critical concern despite the invaluable contribution of ionizing radiation in medical imaging to diagnosis and subsequent treatment of various disease entities (4). Radiation exposure, either from radiation accident or medical X-ray examination at the early stage of life usually results in a likelihood of two or three fold increase in lifetime risk for certain detrimental effects, including solid cancer, compared with that of adult $(1,5)$.

Radiation protection in pediatric radiology requires a more special attention than in adult radiology because in children, ionizing radiation can cause genetic mutations, congenital malformations in the foetus and increase the risk of inducing malignancy in the growing organs and tissues (6). In general, children have a longer life expectancy than adults and are therefore at a greater risk to the long-term side effects of radiation.

To prevent the detrimental effects of ionizing radiation, several international authorities on radiation protection have strictly stipulated three fundamental principles as the bedrock of sound radiological protection. These are justification, optimization and the application of dose limits. They have also provided a range of reference dose in all population, including pediatric age group (79).

It is known that patient doses from X-ray examinations vary widely, even for the same projection (10). The dose variation may be due to patient weight, exposure factors, radiological technique, focus to film distance (FFD), film- screen speed, equipment type and processing performance. This variability can be reduced through quality assurance programmes in hospitals, providing Diagnostic Reference Dose Levels (DRL) for various radiological procedures through Entrance Surface Dose (ESD) and effective dose calculations (10).

Entrance Surface Dose (ESD) has been used to report patient doses, and this has been studied for both adult and pediatric patients in many parts of the world (11). Ethiopia has not recorded similar evidences of research in patient radiation concerns, especially with regard to children, who have greater susceptibility to radiation effects.

In Ethiopia, although there are a large number of medical X-ray units in public and private health institutes, all diagnostic X-ray centers do not have pediatric radiology and X-ray operators use unstandardized exposure parameters and radiographic techniques that are not appropriate for children.

Although a legal framework for the use of ionization radiation in diagnostic and interventional radiology was established in Ethiopia, there is a lack of information on patient radiation dose due to a paucity of studies on patient radiation dose. Therefore, this study was conducted to assess the exposure parameters selected for X-ray examinations of pediatric patients and to estimate the Entrance Surface Dose (ESD) delivered to pediatric patients undergoing common diagnostic X-ray examinations in JUSH, Southwest Ethiopia. The resultsof this study enables the clinicians to know their position on the application of DRL as a practical tool to manage radiation doses on patients in diagnostic radiology, will add to the pool of the existing few data on pediatric dose from medical X-ray examinations in Ethiopia and used as a base line for future work.

\section{MATERIALS AND METHODS}

Hospital based cross-sectional study was conducted on pediatric patients less than 15 years old who visited to seek X-ray examinations in radiology department of JUSH. JUSH is the only specialized hospital in South West Ethiopia, but it

DOI: http://dx.doi.org/10.4314/ejhs.v27i5.6 
does not have a dedicated X-ray facility for children.

The X-ray examination studied were Chest, Skull, Abdomen and Pelvic for anterior posterior (AP) projection. The exposure parameters used and measured for each patient were kilo voltage peak $(\mathrm{kVp})$, product of tube current and time (mAs) and focus-film distance (FFD). To ensureall dose levels used were representative of diagnostic image, only cases with diagnostically acceptable images were considered to be investigated in this study.

A total of 580 children were included in this study. The X-ray machine (model R-20) used was manufactured in the year 1992 by Shimadzu Corporation. The X-ray tube has a total filtration of $1.0 \mathrm{~mm} \mathrm{Al}$ at $70 \mathrm{kV}$ and is powered by 3 -phase type generator. Two manufacturers' cassettes (Agfa and Kodak) were used with a screen-film combination speed of 400. All films were processed using manual processor.

X-ray tube output measurement: The tube out puts of the X-ray machine was measured by dositime $\mathrm{dx}$ digital dosimeter and exposure time meter. Normalization at $80 \mathrm{kV}_{\mathrm{p}} 20 \mathrm{mAs}$ and focus to skin distance (FSD) of $100 \mathrm{~cm}$ was used. Dx dosimeter was calibrated for sensitivity and linearity. Calibration was done with known doses of $\mathrm{X}$-ray at $50 \mathrm{kV}$ to $120 \mathrm{kV}_{\mathrm{p}}$ in $10 \mathrm{kV}_{\mathrm{p}}$ step. Finally, the measured tubes output in unit of $\mathrm{mGy} / \mathrm{mAs}$ for the X-ray tube was calculated by using equation below.

\section{$o_{\mathrm{P}}=\frac{\text { Average Dosimeter Readings }}{\text { tube current time product }(\mathrm{mAs})}$}

Accordingly, the tube output of the X-ray machine was found to be $0.93 \mathrm{mGy} / \mathrm{m}$. The ESD for pediatric patients was calculated in terms of the entrance surface air kerma on the basis of X-ray tube output measurements and X-ray exposure parameters, and it was determined by multiplying the incident air kerma to the patient's skin with an appropriate backscatter factor (BSF) by using the following formula $(12,13)$.

$$
\mathrm{ESD}=(\mathrm{O} / \mathrm{P}) \times\left(\frac{\mathrm{kV} p}{80}\right)^{2} \times(\mathrm{mAs}) \times\left(\frac{100}{\mathrm{FSD}}\right)^{2} \times(\mathrm{BSF})
$$

$(\mathrm{O} / \mathrm{P})$ is the tube output $\mathrm{mGy} / \mathrm{mAs}$ measured at a distance of $100 \mathrm{~cm}$ from the tube focus along the beam axis while $\mathrm{kVp}$ is peak tube voltage recorded for any given examination. mAs is the tube current and time product whereas FSD is the focus-to-patient entrance surface distance and BSF is the backscatter factor. The BSF used in this study was 1.35 (14).

The method of data analysis carried out in this study comprises both qualitative and descriptive statistic. Quantifiable information collected from each radiographic examination was analyzed and presented using mean, maximum, minimum, $\mathrm{SD}, 1^{\text {st }}$ quartile, and $3^{\text {rd }}$ quartile. Charts and tables were also used.

Finally, the results of calculated ESD was compared with international recommended values (DRL) and with similar studies conducted elsewhere.

Confidentiality of information was maintained. Permission from hospital administration and verbal consent from parents of the children was obtained to take measurements.

\section{RESULT}

Results from analysis of radiographic parameters and patients' information: The average radiographic parameters and patient data for pediatric patients with respect to their ages are presented in Table 1. Chest X-ray examination was the frequently performed followed by skull X-ray. In all age groups, the minimum $/$ maximum weights were $5.4 \mathrm{~kg} / 30 \mathrm{~kg}$. It can be seen that the mean tube voltage used for different X-ray examinations varied slightly with the age groups. The minimum mean $\mathrm{kVp}$ selected for all age groups was $40 \mathrm{kVp}$ while the maximum mean $\mathrm{kVp}$ was $100 \mathrm{kvp}$. The mean tube loading (mAs) used in combination with the tube voltage for different X-ray examinations showed that the mean $\mathrm{mAs}$ used for all $\mathrm{X}$-ray examinations performed for age group 0-1 year was between $8 \mathrm{mAs}$ and $14 \mathrm{mAs}$. The minimum mean $\mathrm{mAs}$ for all ages was $5.5 \mathrm{mAs}$ while the maximum mean value was $14 \mathrm{mAs}$. It was seen that the mean mAs increases with increasing patient age for different examinations and different $\mathrm{mAs}$ for the same examinations. 
Table1. Average radiographic parameters and patient data for pediatric patients presenting for X-ray examinations in the JUSH.

\begin{tabular}{|c|c|c|c|c|c|c|c|c|c|c|c|c|c|c|c|c|c|c|c|c|}
\hline \multirow[t]{2}{*}{ Types of Examinations } & \multicolumn{5}{|l|}{$0-1$ years } & \multicolumn{5}{|c|}{$1-5$ years } & \multicolumn{5}{|c|}{$5-10$ years } & \multicolumn{5}{|c|}{$10-15$ years } \\
\hline & $\begin{array}{l}\begin{array}{l}\text { Age } \\
\text { (month) }\end{array} \\
\end{array}$ & $\begin{array}{l}\text { Weight } \\
(\mathrm{kg})\end{array}$ & $\mathrm{kVp}$ & mAs & $\begin{array}{l}\text { FFD } \\
(\mathrm{cm})\end{array}$ & $\begin{array}{l}\begin{array}{l}\text { Age } \\
\text { (yrs) }\end{array} \\
\end{array}$ & $\begin{array}{l}\text { Weight } \\
(\mathrm{kg})\end{array}$ & $\mathrm{kVp}$ & $\mathrm{mAs}$ & $\begin{array}{l}\text { FFD } \\
(\mathrm{cm})\end{array}$ & $\begin{array}{l}\begin{array}{l}\text { Age } \\
(y r s)\end{array} \\
\end{array}$ & $\begin{array}{l}\text { Weight } \\
\text { (kg) }\end{array}$ & $\mathrm{kVp}$ & $\mathrm{mAs}$ & $\begin{array}{l}\text { FFD } \\
(\mathrm{cm})\end{array}$ & $\begin{array}{l}\begin{array}{l}\text { Age } \\
\text { (yrs) }\end{array} \\
\end{array}$ & $\begin{array}{l}\text { Weight } \\
(\mathrm{kg})\end{array}$ & $\mathrm{kVp}$ & mAs & $\begin{array}{l}\text { FFD } \\
(\mathrm{cm})\end{array}$ \\
\hline \multicolumn{21}{|l|}{ Chest AP } \\
\hline Mean & 6.54 & 6.21 & 40 & 8 & 125 & 3.2 & 11.2 & 45 & 5.5 & 125 & 8.72 & 19 & 55 & 7 & 125 & 13 & 27 & 67 & 9 & 125 \\
\hline SD & 3.43 & 1.92 & 2 & 3.2 & 2 & 0.4 & 2 & 3 & 2 & 2 & 4 & 5 & 4 & 2.3 & 2 & 2 & 4 & 3 & 4 & 2 \\
\hline Min & 0.98 & 3.42 & 30 & 6.3 & 100 & 1.5 & 8.2 & 40 & 5 & 100 & 5.5 & 15 & 40 & 5 & 100 & 10.9 & 21 & 60 & 7 & 100 \\
\hline Max & 12 & 9.54 & 45 & 10 & 150 & 4.6 & 15 & 50 & 6.5 & 150 & 9.8 & 20 & 80 & 9 & 150 & 14 & 32 & 90 & 14 & 150 \\
\hline Median & 5.65 & 6.23 & 39 & 8.4 & 150 & 2.6 & 9 & 40 & 5 & 100 & 6.7 & 16 & 65 & 6 & 100 & 12 & 25 & 72 & 10 & 100 \\
\hline S/SIZE & 23 & 23 & 23 & 23 & 23 & 34 & 34 & 34 & 34 & 34 & 80 & 80 & 80 & 80 & 80 & 93 & 93 & 93 & 93 & 93 \\
\hline Mean & 5.4 & 5.9 & 55 & 14 & 150 & 3.3 & 10 & 65 & 6 & 100 & 7.9 & 20 & 80 & 10 & 100 & 12 & 27.8 & 80 & 11 & 100 \\
\hline SD & 2 & 2.5 & 3 & 3 & 0 & 3 & 2.5 & 5 & 3 & 0 & 3 & 5 & 3 & 4 & 0 & 2 & 3 & 5 & 5.4 & 0 \\
\hline Min & 2 & 4.2 & 45 & 9 & 150 & 2 & 8 & 60 & 5 & 100 & 5.4 & 13 & 70 & 7 & 100 & 10.4 & 20 & 70 & 8 & 100 \\
\hline Max & 10.2 & 9.6 & 60 & 18 & 150 & 1.6 & 16 & 70 & 8 & 100 & 9.6 & 21 & 90 & 16 & 100 & 14 & 31 & 100 & 18 & 100 \\
\hline Median & 6.7 & 5.7 & 50 & 15 & 150 & 2.5 & 9.7 & 60 & 6 & 100 & 7 & 17 & 85 & 11 & 100 & 12 & 26 & 85 & 10 & 100 \\
\hline S/SIZE & 12 & 12 & 12 & 12 & 12 & 27 & 27 & 27 & 27 & 27 & 49 & 49 & 49 & 49 & 49 & 57 & 57 & 57 & 57 & 57 \\
\hline Mean & 7 & 7.2 & 60 & 9 & 100 & 4 & 12 & 70 & 8 & 100 & 8 & 20 & 80 & 11 & 100 & 13.5 & 29 & 100 & 12 & 150 \\
\hline SD & 2 & 3 & 2 & 3 & 0 & 3 & 4 & 5 & 2 & 0 & 3 & 4 & 4 & 5 & 0 & 2 & 4 & 5 & 3 & 0 \\
\hline Min & 1 & 5.8 & 55 & 7 & 100 & 1.3 & 8.9 & 60 & 7 & 100 & 5.2 & 14 & 70 & 7 & 100 & 11 & 23 & 90 & 10 & 150 \\
\hline Max & 11 & 10 & 70 & 11 & 100 & 4.8 & 17 & 100 & 10 & 100 & 9.3 & 23 & 100 & 14 & 100 & 14 & 34 & 150 & 15 & 150 \\
\hline Median & 5 & 7 & 60 & 10 & 100 & 2.6 & 10 & 70 & 8 & 100 & 6 & 17 & 80 & 9 & 100 & 13 & 26 & 100 & 13 & 150 \\
\hline S/SIZE & 11 & 11 & 11 & 11 & 11 & 30 & 30 & 30 & 30 & 100 & 47 & 47 & 47 & 47 & 47 & 57 & 57 & 57 & 57 & 57 \\
\hline Mean & & & & & & 3 & 11 & 65 & 10 & 100 & 6 & 19 & 80 & 9 & 100 & 23 & 30 & 90 & 11 & 100 \\
\hline SD & & & & & & 2 & 3 & 3 & 2 & 0 & 2 & 3 & 4 & 3 & 0 & 2 & 3 & 5 & 4 & 0 \\
\hline Min & & & & & & 1.2 & 9 & 60 & 10 & 100 & 5.2 & 16 & 70 & 7 & 100 & 11 & 22 & 80 & 8 & 100 \\
\hline Max & & & & & & 4.8 & 18 & 70 & 11 & 100 & 9.8 & 23 & 90 & 14 & 100 & 14 & 33 & 100 & 14 & 100 \\
\hline Median & & & & & & 2.6 & 9 & 60 & 9 & 100 & 7 & 16 & 70 & 8 & 100 & 12 & 27 & 80 & 12 & 100 \\
\hline S/SIZE & & & & & & 20 & 20 & 20 & 20 & 20 & 32 & 32 & 32 & 32 & 32 & 35 & 35 & 35 & 35 & 35 \\
\hline
\end{tabular}

DOI: http://dx.doi.org/10.4314/ejhs.v27i5.6 
Descriptive statistics (Mean, Median, Minimum, Maximum and Standard deviation) of ESD values obtained in this study is shown in Table 2. In this study, the highest mean ESD (mGy) was seen for skull AP examination for age group 0-1 year. The children in the age group 1-5 year received the lowest mean ESD of $1.72 \mathrm{mGy}$ in the chest and highest mean ESD of $11.05 \mathrm{mG}$ in the pelvic examinations. The highest ESD for age group 5-10 years was from abdomen examinations while age group 10-15 year received the highest ESD from pelvic examinations.

Table 2. Descriptive Statistics (Mean, Median, Minimum, Maximum, and Standard deviation) of ESD values obtained in the study.

\begin{tabular}{llllll}
\hline $\begin{array}{l}\text { Types of } \\
\text { Examination }\end{array}$ & & $\begin{array}{l}\text { Chest } \\
\text { AP }\end{array}$ & $\begin{array}{l}\text { Skull } \\
\text { AP }\end{array}$ & Abdomen AP & Pelvic AP \\
\hline Age (yrs) & ESD (mGy) & & & & \\
& Mean & 1.82 & 8.68 & 7.71 & - \\
$0-1$ & SD & 0.7 & 0.4 & 0.7 & - \\
& Min & 0.97 & 8.03 & 7.11 & - \\
& Max & 2.34 & 9.00 & 8.22 & - \\
& Median & 1.54 & 6.74 & 6.32 & - \\
& Mean & 1.72 & 4.76 & 10.26 & 11.05 \\
& SD & 2.1 & 0.6 & 0.8 & 0.5 \\
$1-5$ & Min & 1.06 & 4.12 & 9.85 & 10.75 \\
& Max & 2.12 & 5.04 & 10.76 & 11.82 \\
& Median & 1.65 & 4.55 & 10.11 & 11.03 \\
$5-10$ & Mean & 3.40 & 6.55 & 19.30 & 15.79 \\
& SD & 0.3 & 0.4 & 0.3 & 0.2 \\
& Min & 2.68 & 5.87 & 18.11 & 15.01 \\
& Max & 3.97 & 6.87 & 19.74 & 16.75 \\
& Median & 3.34 & 6.22 & 18.82 & 16.12 \\
& Mean & 5.87 & 11.97 & 11.12 & 25.03 \\
$10-15$ & SD & 0.2 & 0.5 & 2.0 & 2.7 \\
& Min & 5.10 & 10.45 & 10.31 & 24.53 \\
& Max & 6.23 & 12.53 & 11.76 & 25.78 \\
& Median & 5.86 & 11.20 & 10.75 & 20.32 \\
\hline
\end{tabular}

Table 3 shows the mean ESD, the $1^{\text {st }}$ quartile and the $3^{\text {rd }}$ quartile values of the ESD estimated for the individual examinations. In addition, the Range Factor (RF), defined as the ratio of maximum to minimum dose for the same type of examination, were calculated and are presented in Ttable 3. The range factor, which highlights the spread/variation in the ESD values for the same type of examination, as well as the minimum, maximum, and range factor of ESD values for the same type of examination in the same room (intra-room variation), is also shown in Table 3. In this way, the factor by which the dose of radiation can vary for the same examination in the same room is indicated by the quotient of the highest and the lowest doses for an examination. 
Table 3. Distribution of Mean Entrance Surface Dose values (mGy) for individual patients at JUSH.

\begin{tabular}{llllllll}
\hline \multirow{2}{*}{ Radiograph } & Age(year) & $\begin{array}{l}\text { Min. } \\
\text { ESD(mGy) }\end{array}$ & $1^{\text {st }}$ Quartile & $\begin{array}{l}\text { Mean } \\
\text { ESD(mGy) }\end{array}$ & $3^{\text {rd }}$ Quartile Max. ESD(mGy) & Max/Min \\
\hline Chest AP & $0-1$ & 0.97 & 0.46 & 1.82 & 1.37 & 2.34 & 2.41 \\
& $1-5$ & 1.06 & 0.43 & 1.72 & 1.29 & 2.12 & 2 \\
& $5-10$ & 2.68 & 0.85 & 3.40 & 2.55 & 3.97 & 1.48 \\
& $10-15$ & 5.10 & 1.47 & 5.87 & 4.40 & 6.23 & 1.22 \\
Skull AP & $0-1$ & 8.03 & 1.72 & 8.68 & 6.51 & 9.00 & 1.08 \\
& $1-5$ & 4.12 & 1.19 & 4.76 & 3.57 & 5.04 & 1.22 \\
& $5-10$ & 5.87 & 1.64 & 6.55 & 4.91 & 6.87 & 1.17 \\
& $10-15$ & 10.45 & 2.99 & 11.97 & 8.98 & 12.53 & 1.12 \\
Abdomen AP & $0-1$ & 7.11 & 1.93 & 7.71 & 5.78 & 8.22 & 1.16 \\
& $1-5$ & 9.85 & 2.57 & 10.26 & 7.70 & 10.76 & 1.09 \\
& $5-10$ & 18.11 & 4.83 & 19.30 & 14.48 & 19.74 & 1.09 \\
& $10-15$ & 10.31 & 2.78 & 11.12 & 8.34 & 11.76 & 1.14 \\
Pelvic AP & $0-1$ & - & - & - & - & - & - \\
& $1-5$ & 10.75 & 2.76 & 11.05 & 8.29 & 11.82 & 1.1 \\
& $5-10$ & 15.01 & 3.95 & 15.79 & 11.84 & 16.75 & 1.13 \\
& $10-15$ & 24.53 & 6.26 & 25.03 & 18.77 & 25.78 & 1.05 \\
\hline
\end{tabular}

Comparison of mean ESD of this study with similar studies performed at Black Lion and Yekatit-12 hospitals in Addis Ababa is shown in Table 4. This study shows that the mean ESD (mGy) for chest AP radiography recorded in this work are higher for all age groups than the same work in Black Lion Hospital and Yekatit-12 Hospital in Addis Ababa, Ethiopia (15).

For the abdomen and pelvic radiographs, the mean ESD found in this work is generally higher than the work of Seifa Teferi et al (15). Sometimes, the dose reported in this study is 10 to 25 times larger than the work of Seifa Teferi et al (15).

Comparison of pediatric patients, mean $\operatorname{ESD}(\mathrm{mGy})$ values of this study with internationally published studies amnd DRL is presented in Table 5. The mean ESD found in this study for chest AP \& abdomen AP is higher than the values published in studies in Nigerian and Brazilian hospitals as well as the reference level recommended by NRPB $(16,17,18)$. For skull AP examinations, the highest mean ESD was found in a Nigerian hospital than this work for the age group (1-5yrs).

Comparison of radiographic techniques and mean ESD ( $\mu \mathrm{Gy})$ for chest AP examination with different internationally published studies is shown in Figure 1. As it can be seen from the figure, low $\mathrm{kVp}$ was used in this study for the age group (0-yrs1) and (1-5yrs)compared to Addis Ababa and FMCO hospitals. Higher/lower tub loading (mAs) was used in this study compared to FMCO and Khartoum hospitals/Yekatit 12 Hospital. 
Assessment of Pediatrics Radiation Dose...

Mesfin Z. et al.

Table 4. Comparison of mean ESD (mGy) results with studies in Addis Ababa hospitals.

\begin{tabular}{lllll}
\hline $\begin{array}{l}\text { Type of } \\
\text { Examinations }\end{array}$ & Age yrs Jimma & \multicolumn{2}{l}{ Addis Ababa } \\
\cline { 2 - 5 } & & JUSH & $\begin{array}{l}\text { Black Lion } \\
\text { Hospital }\end{array}$ & $\begin{array}{l}\text { Yekatit 12 } \\
\text { Hospital }\end{array}$ \\
\hline Chest AP & $0-1$ & 1.82 & 0.10 & 0.20 \\
& $1-5$ & 1.72 & 0.19 & 0.25 \\
& $5-10$ & 3.40 & 0.12 & 0.28 \\
Skull AP & $10-15$ & 5.87 & 0.12 & - \\
& $0-1$ & 8.68 & 0.39 & 0.51 \\
& $1-5$ & 4.76 & 1.13 & 0.83 \\
Abdomen AP & $5-10$ & 6.55 & 1.16 & 1.43 \\
& $10-15$ & 11.97 & 1.52 & 3.19 \\
& $1-5$ & 7.71 & 0.19 & 0.32 \\
Pelvic AP & $5-10$ & 10.26 & 0.19 & 0.37 \\
& $10-15$ & 11.12 & 0.50 & 0.84 \\
& $0-1$ & - & 1.55 & 0.94 \\
& $1-5$ & 11.05 & - & 0.27 \\
& $5-10$ & 15.79 & 0.25 & 0.38 \\
& $10-15$ & 25.03 & 0.44 & 1.12 \\
& & & 1.44 & 1.79 \\
\hline
\end{tabular}

Table 5: Comparison of the Mean ESD (mGy) obtained in the Present Study with Some International Published studies and Reference Dose Values.

\begin{tabular}{|c|c|c|c|c|c|c|c|}
\hline \multirow{2}{*}{$\begin{array}{l}\text { Type of } \\
\text { Examinations }\end{array}$} & Age group & Ethiopia & \multicolumn{2}{|c|}{ Nigeria } & \multicolumn{2}{|l|}{ Brazil } & \multirow{2}{*}{$\begin{array}{l}\text { DRL } \\
\text { NRPB }\end{array}$} \\
\hline & & JUSH & UCTH & FMCO & HMG & IFF & \\
\hline & $0-1$ & 1.82 & 0.642 & 0.072 & 0.052 & 0.067 & 0.050 \\
\hline \multirow[t]{4}{*}{ Chest AP } & $1-5$ & 1.72 & 1.821 & 0.125 & 0.063 & 0.077 & 0.070 \\
\hline & $5-10$ & 3.40 & 1.704 & 0.146 & 0.064 & 0.079 & - \\
\hline & $10-15$ & 5.87 & - & - & - & - & - \\
\hline & $0-1$ & 8.68 & 6.224 & 0.114 & 1.233 & 0.597 & 0.800 \\
\hline \multirow[t]{4}{*}{ Skull AP } & $1-5$ & 4.76 & 5.156 & 0.105 & 1.603 & 0.736 & 1.100 \\
\hline & $5-10$ & 6.55 & - & - & 2.041 & 0.754 & 1.100 \\
\hline & $10-15$ & 11.97 & - & - & 2.554 & 0.812 & 1.100 \\
\hline & $0-1$ & 7.71 & 1.835 & 0.135 & - & 0.242 & - \\
\hline \multirow[t]{4}{*}{ Abdomen AP } & $1-5$ & 10.26 & - & - & 0.714 & 0.277 & 0.500 \\
\hline & $5-10$ & 19.30 & - & 0.406 & 1.238 & 0.308 & 0.800 \\
\hline & $10-15$ & 11.12 & 6.605 & 1.205 & - & 0.454 & 1.200 \\
\hline & $0-1$ & - & 1.824 & 0.075 & 0.513 & - & 0.500 \\
\hline \multirow[t]{3}{*}{ Pelvic AP } & $1-5$ & 11.05 & - & - & 0.797 & - & 0.600 \\
\hline & $5-10$ & 15.79 & - & -- & 1.286 & - & 0.700 \\
\hline & $10-15$ & 25.03 & - & - & 1.816 & - & 2.00 \\
\hline
\end{tabular}

DOI: http://dx.doi.org/10.4314/ejhs.v27i5.6 


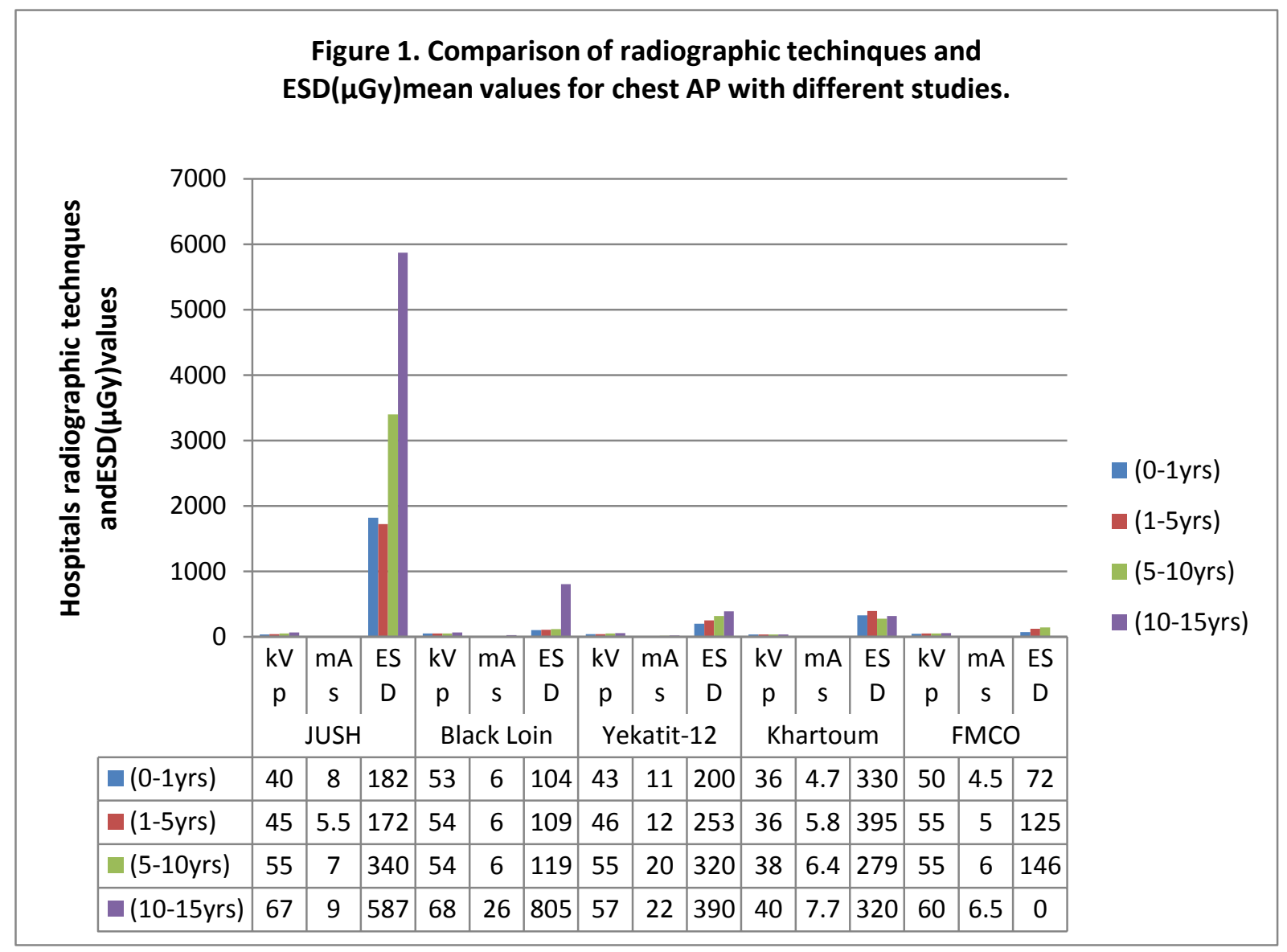

\section{DISCUSSION}

In this study, ESD received by 580 pediatric patients under 15 years were calculated. It can be seen in Table 1 that the tube voltage used for different X-ray examinations varied slightly with the age group. The European Commission (19) recommended the use of tube voltage values of $60-80 \mathrm{kVp}$ for ages $0-1$ year; and $100-120 \mathrm{kVp}$ for ages 5 years and above. They also discouraged the use of tube voltage less than 60 $\mathrm{kVp}$ for pediatric patient. Examinations of the mean tube potential $(\mathrm{kVp})$ and tube loading $(\mathrm{mAs})$ chosen in JUSH demonstrated that low tube potentials, and high tube loadings were used for all types of X-ray examinations and for all age groups.

This X-ray department was performing its radiological practices with tube voltage of $40-60 \mathrm{kVp}$ for age group (0-1yrs); $45-70 \mathrm{kVp}$ for the age group (1-5yrs) and 55-100kvp for ages 5 years and above. These values are much less than the value recommended by the European Commission and other international guidelines as good radiographic practices to maintain a balance between an optimized patient dose and good diagnostic image. However, the radiographers in the study hospital could not give any reason for the use of low tube voltages, other than the fact that it gives acceptable images. Both low and high $\mathrm{kVp}$ techniques were reported to be commonly used in routine radiographic examinations in Europe and the USA (20), but it has been shown that the use of a high voltage technique for the routine $\mathrm{X}$-ray examination has been calculated to reduce entrance surface dose by half and effective dose equivalent by $20 \%$. Therefore, values lower than therecommended tube potentials should not be used $(21,22)$.

Very high mean mAs were used compared to the internationally recommended value. It was seen that the mean $\mathrm{mAs}$ increases with increasing patient age for different examinations and different $\mathrm{mAs}$ for the same examinations.

The FFD employed in this study was very small and similar for each examination. FFDs as low as 90$150 \mathrm{~cm}$ were used instead of $180 \mathrm{~cm}$ recommended by CEC guidelines for quality radiography examinations

DOI: http://dx.doi.org/10.4314/ejhs.v27i5.6 
(23). The use of optimum FFD is considered very important since a direct relationship between shorter FFD, higher patients' dose and decreased geometric sharpness has been well established. Since ESD is inversely proportional to the square of the FFD, for the same $\mathrm{kVp}$ and $\mathrm{mAs}$, the dose reaching the patient is expected to be high. The general trend in this hospital is the use of lower FFDs and this, in part, might explain higher ESDs. This indicates that the results do not show this as a universal trend (some centers with low FFDs present lower mean ESDs, some much, much higher). It is worth noting that changing FFD could be a good change, but will still not solve all discrepancies found in the study. It is therefore essential that policies on quality control and quality assurance monitoring programmes be enforced in the hospital to protect the patient from unnecessary exposures through repeat examinations.

Generally, the radiographic technique parameters recorded in this study revealed that there were variations in the technique factors when compared with the recommendations in the EC quality criteria (24). Varying radiographic voltages and reduced focus film distances were used. All these factors have adverse influences on the outcome of the dose to patients. The above problem was not specific to Ethiopia, but is common in other developing countries as well (25). These problems probably could partly be associated with the inadequate training of imaging staff, variation in patient physical appearance, different types of equipment, and variety of techniques used in different hospitals. Therefore, dose reduction would be possible without adversely affecting image quality through training and regular provision of dose information. This involves collaboration between medical physicists, radiographers and radiologists.

Comparison between the present measurements and those from internationally established reference dose levels revealed that mean ESD values in our study are higher than DRL and internationally published studies $(26,27,28)$. This can be attributed to non-availability of dedicated X-ray unit for pediatric radiology in Ethiopian hospitals and inadequate trained personnel.

Based on the result of this study, the researchers recommend the following points:

- It is abvisable to use low kvp and high mAs which improves image quality while increasing dose to the patient must be changed so that the dose should be maintained as low as reasonably achieved (ALARA) principles.
- Dose reduction would be possible without adversely affecting image quality by providing training and regular provision of dose information.

- The national radiation protection authority should conduct intra-hospital and inter hospital survey, monitor doses of radiation and subsequently develop radiation protection reference dose levels for the country.

- A culture of regular dose measurements, film rejects analysis and image quality assessment as recommended by the IAEA need to become part of diagnostic radiology procedures in the country.

- Pediatric radiology units should be separated if possible since children need special attention to minimize the dose and the risks.

- Finally, the researchers recommend that further large scale dose surveys in every diagnostic radiology unit in the country should be undertaken so as to develop diagnostic reference dose level (DRL) at the national level.

\section{ACKNOWLEDGEMENTS}

We would like to acknowledge Jimma University, College of Health Science Postgraduate Office for fully funding this work. Finally, we would like to thank all data collectors and all individuals who contributed to this work.

\section{REFERENCES}

1. United Nations Scientific Committee on the Effects of Atomic Radiation Sources. Effects and Risks of Ionizing Radiation. UNSCEAR Report, Vol. II: effects. New York, 2000.

2. Muhogora WE, Nyanda AM. The potential for reduction of radiation doses to patients undergoing some common $\mathrm{X}$ - ray examinations in Tanzania. Radiat Prot. Dosim. 2001: 94:381-384.

3. Busberg JT, Seibert JA, Leiholdt EM, Boone JM. The Essential Physics of Medical Imaging. $2^{\text {nd }}$ ed. Philadelphia, Pa: Lippincott Williams \& Wilkins, 2002; 14:11-24.

4. Bo Hyun Kim, Kyung-Hyun Do, Hyun Woo Goo, et al. National Survey of Radiation Doses of Pediatric Chest Radiography in Korea: Analysis of the Factors Affecting Radiation Doses. Korean J. Radiol.2012; 13: 610-617.

5. Mohamadain KEM, Azevedo ACP. Radiation dose survey in conventional pediatric Radiology. J. Sc. Tech.2009; 10:175-183. 
6. ICRP, Radiological protection in paediatric diagnostic and interventional radiology. Annals of the ICRP, 2011; 48393982-4649.

7. International Commission for Radiological Protection Publication. The Recommendations of the International Commission on Radiological Protection. Publication 103, Oxford and New York: Pergamon Press; 2007.

8. NRPB, Patient Dose reduction in diagnostic Radiology. NRPB, 1990; No. 3. Vol 1.

9. International Atomic Energy Agency. IAEATECDOC - 796. Vienna: Radiation Doses in Diagnostic Radiology and Methods for Dose Reduction; 1995.

10. Mohamadain KEM, Azevedo ACP. Radiation dose survey in conventional pediatric radiology. J. Sc. Tech. 2009; 10:175-184.

11. Azevedo AC, Oibote MC. Pediatric X-ray examinations in Rio de Janeiro. J. Phys. Med. Bio. 2006; 51: 3723-23.

12. Olowookere CJ, Babalola IA, Olayiwola MO, Odina G, Obed RI, Bello TO. Comparison of Five Models for Assessing Patient Dose from Radiological Examinations. Afr. J. Med. Phy. Biomed. Eng \& Sc. 2009; 21-29.

13. Suliman II, Elshiekh HA. Radiation in paediatric X-ray examinations in Sudan. Rad Prot. Dosim.2008; 132:64-72.

14. Suliman II, Abbas N,Habbani FI. Entrance Surface Doses to Patients under going Selected Diagnostic $\mathrm{X}$-ray Examinations in Sudan. Oxford university press, 123, 209-214, 2006.

15. Seifa Teferi, Daniel Adimase, Tekle Abate. Enterance surface dose Measurement in Pediatric Patients under- Going Common Diagnostic X-ray Examinations. Ethi. J. Heal \& Dev. 2011; 49: 51.

16. Ogundare FO, Ajibola CL, Balogun FA. Survey of technique and dose of children undergoing some common x-ray examinations in three hospitals in Nigeria. J. Med. Phys. 2004; 31: 521-4.

17. Mohammadain KE, Rossa LA, Zevedo CA, Gvebel MR. Dose evaluation for pediatric chest examination in Brazil and Sudan. Low doses and reliable examinations can be achieved in developing countries. J. Phys. Med. BIO. 2004; 49: 1017-1031.

18. Hart D, Wall BF, Schrimpton PC, Bungay DR, Dance DR. Reference doses and patient size in paediatric radiology. National Radiation
Protection Board. Report-318.Chilton: HMSO; 2000.

19. European Commission. European Guidelines on Quality Criteria for Diagnostic Radiographic Images in Paediatrics, EUR 16261, EN, Luxembourg; 1996.

20. Medical Imaging Center, University of Helsinki, Helsinki, Finland Summary, Acta Radiologica 2009;50(1) 114-124.

21. NATIONAL RESEARCH COUNCIL, Improving Risk Communication, National Academy Press, Washington, DC.1989

22. Radiological parameters and radiation doses of patients undergoing abdomen, pelvis and lumbar spine X-ray examinations in three Nigerian hospitals, Radiation Protection Dosimetry 21. Advance Access published September 17, 2008, Radiation Protection Dosimetry (2008), pp. 19doi:10.1093/rpd/ncn23

23. European guidelines on quality criteria for diagnostic radiographic images. Report EUR16260. National protocol for patient dose measurements in diagnostic radiology. Report of the Working Party of the Institute of Physical Science in Medicine. Chilton Didcot, NRPB. 1992.

24. Commission of the European Communities. European guidelines on quality criteria for diagnostic radiographic images. EUR16260EN Luxembourg, 1996.

25. Suliman II, Elshiekh EH. Radiation Dose from Some Common Pediatric $\mathrm{x}$-ray Examinations in Sudan. Rad. Prot. Dosim. 2008; 196: 1-4.

26. Hart D, Wall BF, Schrimpton PC, Bungay DR, Dance DR. Reference doses and patient size in paediatric radiology. National Radiation Protection Board. Report-318.Chilton: HMSO. 2000.

27. Ogundare FO, Ajibola CL, Balogun FA. Survey of technique and dose of children undergoing some common $\mathrm{x}$-ray examinations in three hospitals in Nigeria. J. Med. Phys. 2004; 31: 521-524.

28. Mohammadain KE, Rossa LA, Zevedo CA, Gvebel MR. Dose evaluation for pediatric chest examination in Brazil and Sudan. Low doses and reliable examinations can be achieved in developing countries. J. Phys. Med. BIO. 2004; 49: 1017-31. 